\title{
Sponsorship of the CAG: 2001 and beyond
}

I In a previous CAG News Page, we notified CAG members of a change in the sponsorship approach for the CAG. To date, funds to support the CAG having mainly been derived from excess revenue from the annual Canadian Digestive Diseases Week (CDDW) meeting, and in the case of research grants and fellowships, from partnerships with the pharmaceutical industry and the Canadian Institutes of Health Research. Research partnerships and funding will remain unaltered; however, the CAG is now budgeting the annual CDDW meeting to achieve only modest revenue in excess of costs. The funds to maintain the CAG activities beyond the annual CDDW meeting (eg, National Office, educational activities, committee activities/projects, Web site, etc) will be sought through corporate sponsorship. Much of the above change has occurred after discussion with our Industry-Liaison Subcommittee and careful consideration of the best way forward for all parties.

In the spring of 2001, the CAG launched its corporate sponsorship program. Detailed packages were distributed to all potential sponsors (35) with a target of having the program in place during the autumn of 2001. We have carefully designed three levels of corporate sponsorship benefactor, partner and supporter - with each level including set benefits. We also offered incentives for sponsors to commit for longer periods, hence allowing the CAG to do strategic, longer term planning.
We are happy to report that we currently have 12 corporate sponsors of the CAG. Seven of these have committed for a period of three years. We are extremely appreciative of our corporate sponsors and their willingness to embark on this new sponsorship program; for many, already a long term commitment. Please join us in welcoming and thanking them!

\section{BENEFACTORS}

Abbott Laboratories Ltd: Three-year commitment AstraZeneca Canada Inc: Three-year commitment Axcan Pharma Inc: Three-year commitment

\section{PARTNERS}

Ferring Pharmaceuticals: Three-year commitment Hoffmann-La Roche Ltd: Three-year commitment Schering Canada Inc: Three-year commitment Solvay Pharma Inc: Three-year commitment Proctor \& Gamble Pharmaceutical Canada Inc: One-year commitment

\section{SUPPORTERS}

Byk Canada Inc: One-year commitment Carsen Group Inc: One-year commitment Organon Canada Ltd: One-year commitment Pentax Precision Instrument Corp: One-year commitment

\section{Information and details for the 2002 Canadian Digestive Diseases Week available on the CAG Web site http://www.cag-acg.org}




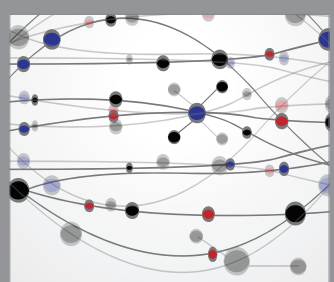

The Scientific World Journal
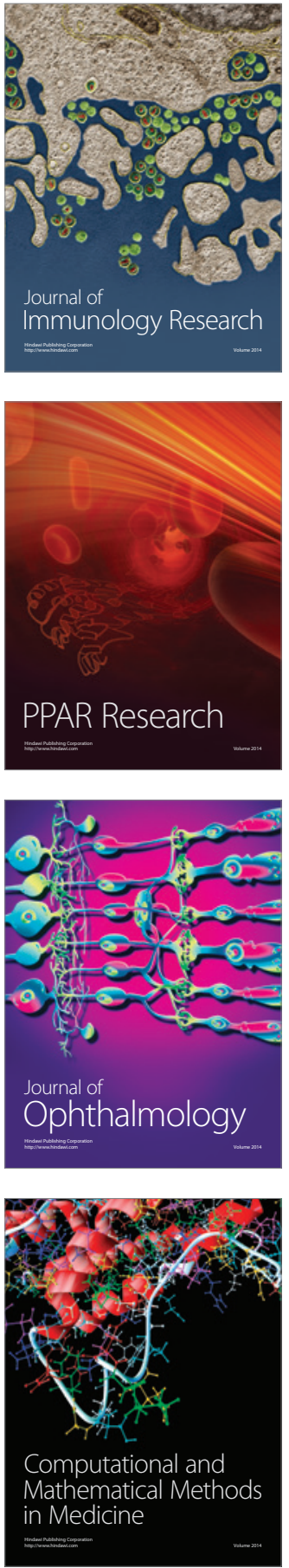

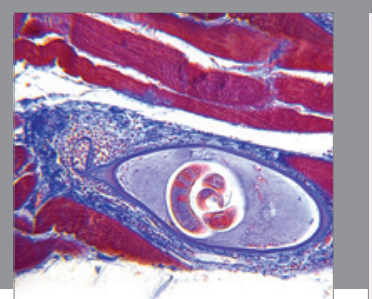

Gastroenterology Research and Practice

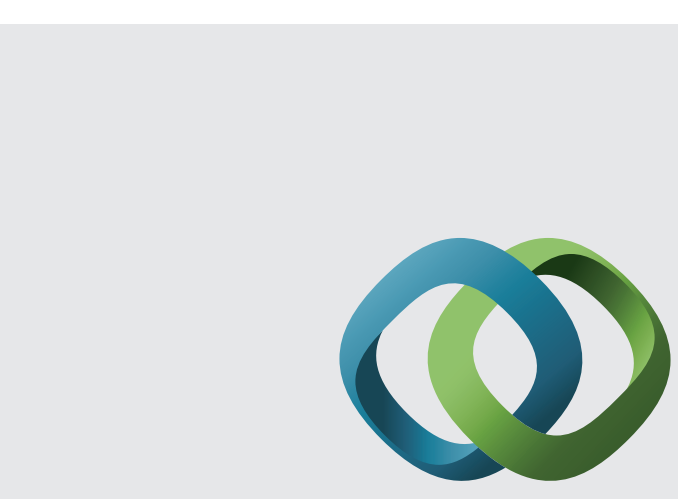

\section{Hindawi}

Submit your manuscripts at

http://www.hindawi.com
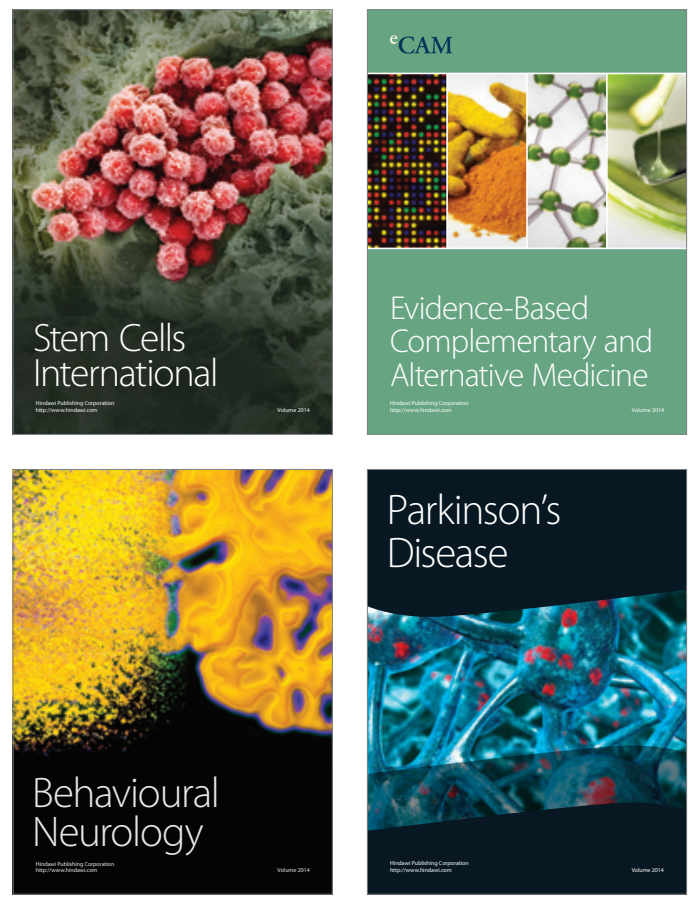
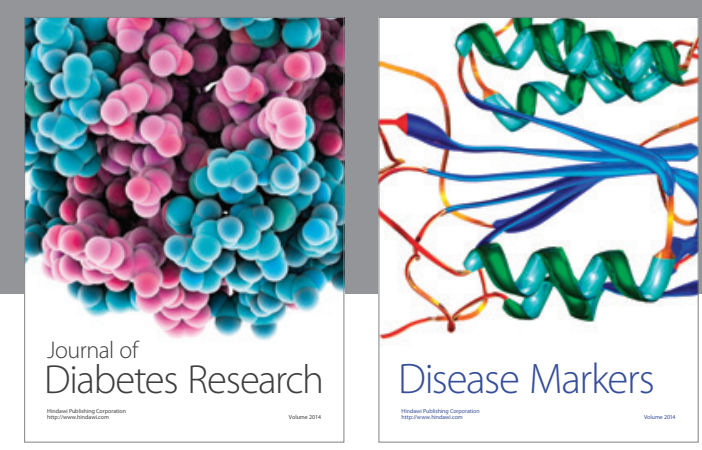

Disease Markers
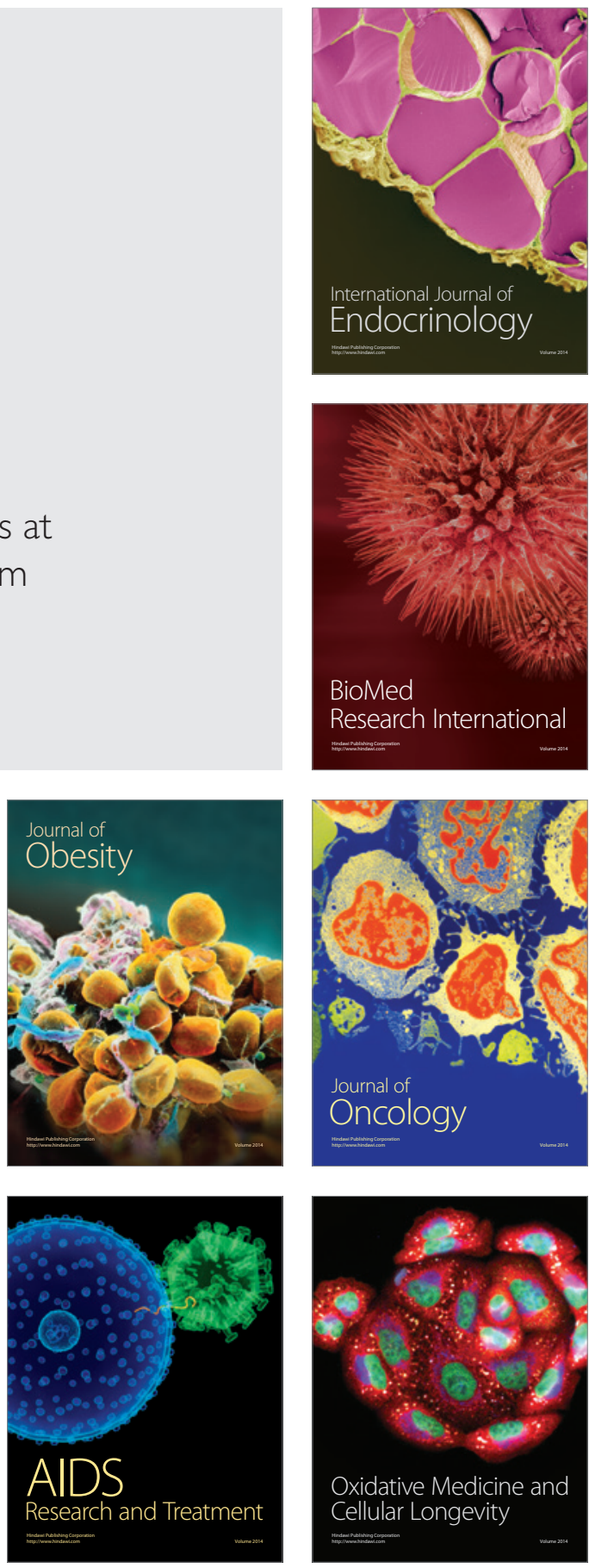